\title{
Removal of Mixed Heavy Metals and Pahs by Immobilized Selenastrum Capricornutum
}

\author{
Nora Fung-Yee Tam ${ }^{1}$, Ping Wang ${ }^{1}$, Dan Deng ${ }^{1}$, and Yuk-Shan Wong ${ }^{2}$ \\ ${ }^{1}$ Department of Biology and Chemistry, City University of Hong Kong, Tat Chee Avenue, Hong Kong SAR, China \\ bhntam@cityu.edu.hk; pingwang@aliyun.com; danicadeng@gmail.com \\ ${ }^{2}$ School of Science and Technology, Open University of Hong Kong, Homantin, Hong Kong SAR, China \\ yswong@ouhk.edu.hk
}

\section{Extended Abstract}

Due to rapid industrialization and urbanization, toxic pollutants are found in industrial discharges causing serious environmental problems. Polycyclic aromatic hydrocarbons (PAHs) from all combustion and industrial activities are released into environments and biomagnified through food chains resulting hazards to humans and wildlife due to their persistence and toxicity. PAHs from industries such as hydrocarbon processing, iron/steel manufacturing, electronic manufacturing, dye manufacturing, electroplating, smelting, etc. are often co-contaminated with high levels of toxic heavy metals (HMs), particularly, cadmium $(\mathrm{Cd})$, copper $(\mathrm{Cu})$, zinc $(\mathrm{Zn})$ and nickel $(\mathrm{Ni})$. These pollutants must be removed prior to discharge. However, the removal of single pollutant could be different from that that under co-contamination with other pollutants, as interactions could occur between pollutants. Microalgae have been reported to have the ability to remove and degrade organic and inorganic pollutants in wastewater. Nevertheless, previous research mainly reported the removal of single pollutant with little consideration on the wastewater containing mixed pollutants. One of the major operation problems encountered in microalgal-wastewater treatment is the difficulty in separating the biomass from the treated effluent, due to the small particle size and low strength and density of the microalgal cell. Such harvesting problem in wastewater could be overcome by the immobilization of microalgal cells within a suitable matrix. However, the removal efficiency of immobilized cells may not be the same as that by the free cells. The present study aimed to investigate the simultaneous removal of mixed heavy metals $(\mathrm{Cu}, \mathrm{Zn}, \mathrm{Ni}$ and $\mathrm{Cd})$ and polycyclic aromatic hydrocarbons (PAHs) of different molecular weights (fluorene, phenanthrene, fluoranthene, pyrene and benzo[a]pyrene) by alginate-immobilized beads of a freshwater commercial green microalgal species, Selenastrum capricornutum, and the feasibility of using immobilized microalgal beads for wastewater treatment.

Results showed that the alginate-immobilized $S$. capricornutum beads could remove 60 to $87 \%$ of $\mathrm{Cu}, \mathrm{Zn}, \mathrm{Cd}$ and $\mathrm{Ni}$, and higher removal percentages were found at the high contamination level of $\mathrm{Cu}: \mathrm{Zn}: \mathrm{Ni}: \mathrm{Cd}$ at 1:1:1:2.5:0.1 $\mu \mathrm{g} \mathrm{mL} \mathrm{mL}^{-1}$. The ranges of removal were $65-85 \%$ for $\mathrm{Cu}, 62-78 \%$ for $\mathrm{Zn}, 60-73 \%$ for $\mathrm{Ni}$ and $80-87 \%$ for $\mathrm{Cd}$. These removal percentages were higher than that observed in free cells of the same species, particularly for $\mathrm{Ni}$ and $\mathrm{Cd}$, the two non-essential metals, as free cells only achieved the highest removal of $19.5 \pm 1.4 \%$ of $\mathrm{Ni}$ and $44.3 \pm 1.6 \%$ for $\mathrm{Cd}$. The removal of heavy metals by microalga beads was significantly reduced by PAHs, except Ni. The inhibitory effect of PAHs on HM removal by immobilized alga beads was less severe compared to that by free cells, as the reduction in the removal of $\mathrm{Cu}, \mathrm{Zn}, \mathrm{Ni}$ and $\mathrm{Cd}$ by PAHs in free cells could reach $28.5 \%, 45.8 \%, 14.1 \%$ and $11.2 \%$, respectively on Day 7 . These results indicated that alginate matrix not only provides more binding sites for HMs, especially non-essential metals such as $\mathrm{Ni}$ and $\mathrm{Cd}$, but also offers protection to algal cells from toxicity due to HMs and PAHs.

The removal of fluorene, phenanthrene, fluoranthene, pyrene and benzo[a]pyrene in a mixture by microalga beads on Day 7 were $70.5 \%, 82.3 \%, 95.8 \%, 96.3 \%$ and 93.6\%, respectively. Alga beads enhanced the removal of low molecular weight (LMW) PAHs, as the removal percentages were significantly higher than that by blank beads. The removal of fluorene and phenanthrene by alga beads was $28.2 \%$ and $19.3 \%$ higher than by blank beads, respectively. However, the removal percentages of high molecular weight (HMW) PAHs were comparable between blank and alga beads, and all had more than 90\% removal from Day 4 onwards. Heavy metals at three contamination levels did not have any significantly effects on the removal of PAHs by immobilized microalga beads, but significantly reduced the amounts of fluorene and pyrene adsorbed onto algal beads while increased the un-accountable fraction of fluorene, phenanthrene and pyrene. 
This study is the first time reporting that alginate-immobilized microalgal beads could simultaneously remove mixed PAHs and heavy metals from wastewater but some interferences between these two types of pollutants occurred. The presence of PAHs reduced the removal of mixed heavy metals while the presence of mixed heavy metals negatively affected the degradation of PAHs after their adsorption and absorption by microalga beads. The algal cells immobilized in alginate matrix not only be protected from the toxicity of the mixed pollutants, immobilization also enhanced the removal percentages when compared with the respective free cells. 